\title{
Investigation of rutilizing additive influence in hydrated titanium dioxide at thermal processing
}

\author{
A.S Kantaev ${ }^{1, a}$, A.L Lashtur ${ }^{1}$, R.I. Kraydenko ${ }^{1}$ and A.N. Dyachenko ${ }^{1}$ \\ ${ }^{1}$ National Research Tomsk Polytechnic University, 634050,Tomsk, Russia
}

\begin{abstract}
The influence of a rutilizing additive in hydrated titanium dioxide is studied at its dehydrationwithin the range of temperaturesfrom 100 to $230^{\circ} \mathrm{C}$. The quantityof major impurities isdetermined using an atom-emission spectrometer. Also, the X-ray diffraction analysis of obtained samplesis performed.
\end{abstract}

\section{Introduction}

Heterogeneous reactions occupy a dominant position in the technologies of rare, scattered, and radioactive elements. The majority of processes belong to this type of reactions. The processes of dehydration and calcinationare accompanied by boiling and vaporization. The multistage sequential flowof a process and the product formationare the main features of heterogeneous reactions. The main objective of heterogeneous kinetics is to determine arate-limiting stage of a technological process and the rate of the whole process. All the processes have a multistage character, and it is impossible to separate individually each stage, therefore, the total energy of activation is determined, which consists of elementary steps [1]. The activation energy is a criterion of the rate-limiting stage. The higher activation energy is, the more difficult formolecules to interact, and the slower the whole process runs. The activation energy is associated with a rate constant. It is possible to determine the rate constant experimentally [2]. Determination of kinetic parameters is confined to measuring the rate of reaction at varioustemperatures; it is definedas mass-change of one of reacting substances in time [2].

Hydrated titanium dioxide (HTD) has a complex molecular structure, and it could contain a variable amount of hydroxyl groupstied with titanium. At thermal processing of HTD the processes of dehydration and polymorphic transformation of anataseinto rutile occur. In this case, the temperature range, in which these processes are implemented, depends, to a large extent, on conditions of HTD obtainment, the size of its crystals, the presence of impurities, and other parameters.

\section{Experimental}

At carrying out the work kinetic research of HTD thermal processing has been conducted with a rutilizing additive and without it at various temperatures. The installation for kinetic researchis shown in Figure 1.

\footnotetext{
$\overline{{ }^{1} \text { Corresponding author: akantaev@tpu.ru }}$
} 


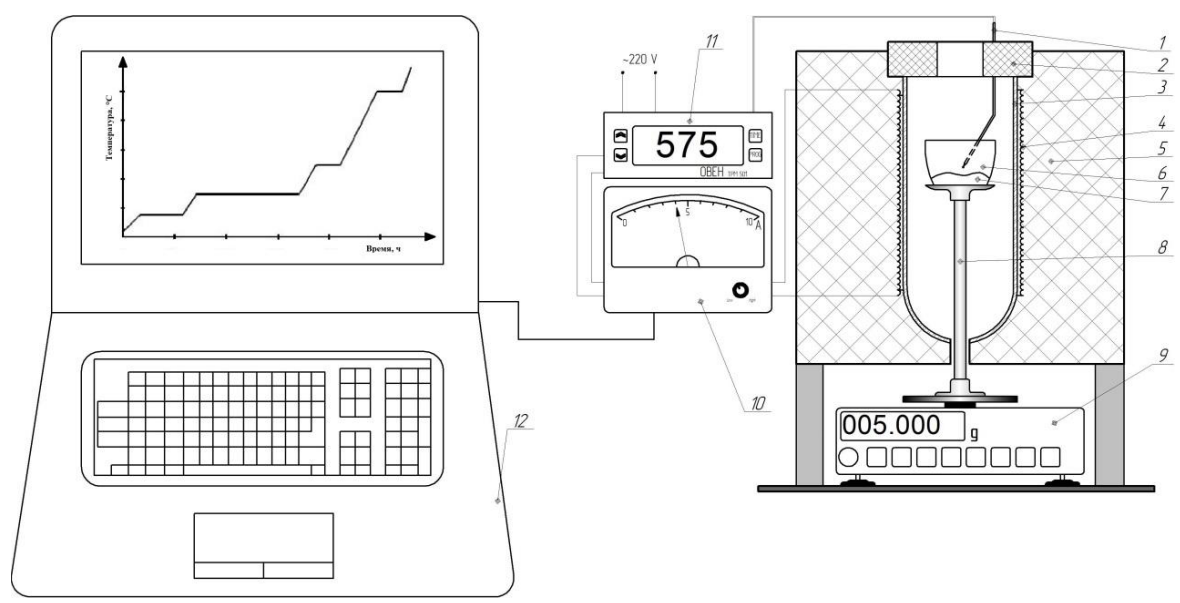

Figure 1.Scheme of a kinetic installation: 1 -a thermocouple; 2 - a cover; 3 - a quartz tube; 4 -an electric heating tube; 5 -heat insulation; 6 - a platinum crucible; 7 -a weighted amount of the studied substance; 8 -a crucible stood; 9 -an electronic weighing machine; 10 -an ammeter; 11 -a programmable thermostat controller "OVEN" TPM 501;12 - a personal computer.

The weighted amounts of hydrated titanium dioxide $(11 \mathrm{~g})$ were dissolved in chlorohydric acid at $\mathrm{pH}=2$ with the addition of zinc metal $(\mathrm{Zn})$, or aluminum $(\mathrm{Al})$ as a rutilizing additive. After 3 hours of reaction the unreacted metal was removed from the solution, and then the $25 \%$ aqua-ammonia solution was added to $\mathrm{pH}=8$. The resulting precipitate was separated from the solution, and it was washed with distilled water. The resulting precipitate was studied usingthe kinetic installation, the process of dehydration was examined according to weight loss, which was, mainly, caused by $\mathrm{H}_{2} \mathrm{O}$ evaporation and $\mathrm{NH}_{3}$ excess. The drying temperature varied from $100^{\circ} \mathrm{C}$ to $230^{\circ} \mathrm{C}$, dehydration time - from 1 to 3 hours[3].

The structure of acrystal lattice in the samplesobtained after thermal processingwas determinedusing the X-ray diffraction analysis (XRD)atthe X-ray diffractometer XRD-7000S of Shimadzu Company. The content of major impurity elements was defined at the atomic emission spectrometer iCAP 6300 Duo of Thermo Electron Corporation Company [4].

\section{Resultsand discussion}

The experimental data for constructingdependence diagramsof mass-change on time were obtainedat various temperatures, using the installation at HTD thermal processing with a rutilizing additive and without it. The results are shown in Figure 2.
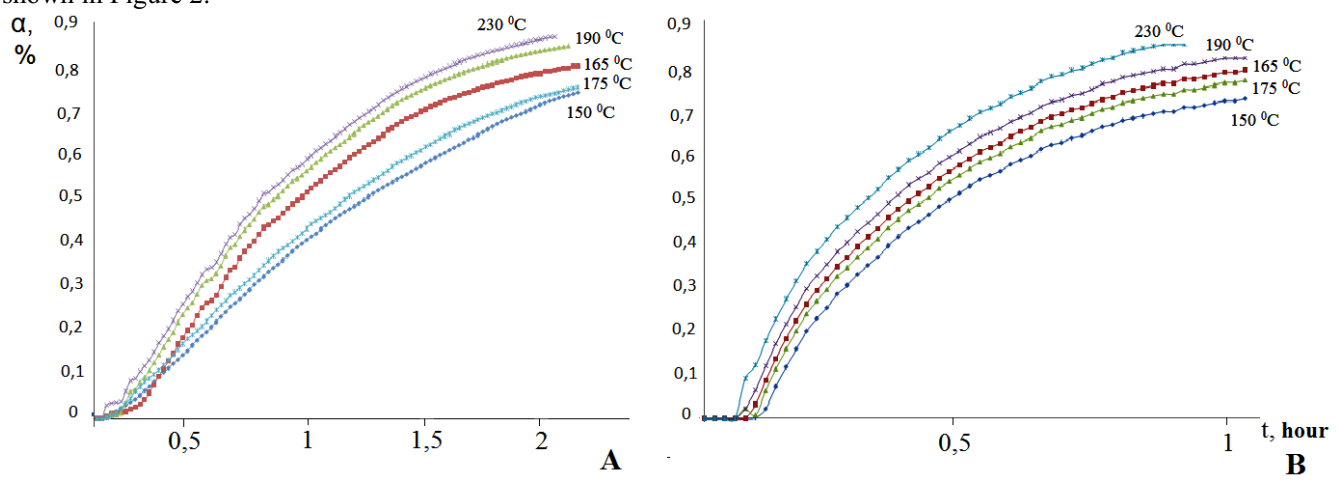

Figure 2.Dependence of water removal rate fromhydrated titanium dioxide on time at various temperatures: A -without adding a rutilizing additive; $\mathrm{B}$ - with adding a rutilizing additive.

Initially, a dehydration process runs intensively with kinking at $\alpha \sim 0.8$, the temperature of $190-230^{\circ} \mathrm{C}$ (after, approximately, 40 minutes). The processes proceed evenly at the temperature below $190^{\circ} \mathrm{C}$, similar to the processes with addition of therutilizing additive - zinc metal.

The process of HTD dehydration proceeds with evenlydependence of mass-change on time (Figure 2). Several sections with different rates of evaporation are traced in all dependencies: the first section -HTD heating for 10 
minutes, the second section - intensive water evaporation (generation and volatilization of gases), and thenthe processes achieve a plateau, where dehydration occurs. The rate of water evaporation increases with the increase of a temperature.Application of a rutilizing additive influencesthermal decomposition, and the process runs faster than without rutilization.

The activation energy of the process is of $2356.3 \mathrm{~J} / \mathrm{mol}$ within the range of temperatures from $150^{\circ} \mathrm{C}$ to $230^{\circ} \mathrm{C}$ (Figure $2 \mathrm{~A}$ ).

For this process the dependence of waterremoval rate from the precipitate on the time and temperature is as follows:

$$
\alpha=1-\left(1-2,4 \cdot \exp \left(-\frac{2356,3}{R \cdot T}\right) \cdot t\right)^{3}
$$

The process runs in an intra-diffusion reaction area.It is determined by a dense structure of hydrated titanium dioxide and also by the complexity of water evaporation through a HTD isolation layer. The process can be intensified using mechanical mixing.

The activation energy of the process is of $1107.8 \mathrm{~J} / \mathrm{mol}$ within the range of temperatures from $150^{\circ} \mathrm{C}$ to $230^{\circ} \mathrm{C}$ at $\mathrm{HTD}$ drying with the use of rutilizing additives (Figure $2 \mathrm{~B}$ ).

Water removal rate in the given range is calculated as follows:

$$
\alpha=1-\left(1-2,4 \cdot \exp \left(-\frac{1107,8}{R \cdot T}\right) \cdot t\right)^{3}
$$

Consequently, the process of dehydration runs in the intra-diffusionreaction area,and it is limited by the diffusion of resultants in pores. The method used to stimulate the process is mechanical mixing.

According to the results of the samples studied using the X-ray diffraction analysis, it is observed that recrystallization of an anatase formintoa rutile oneoccurs as a result of thermal processing.

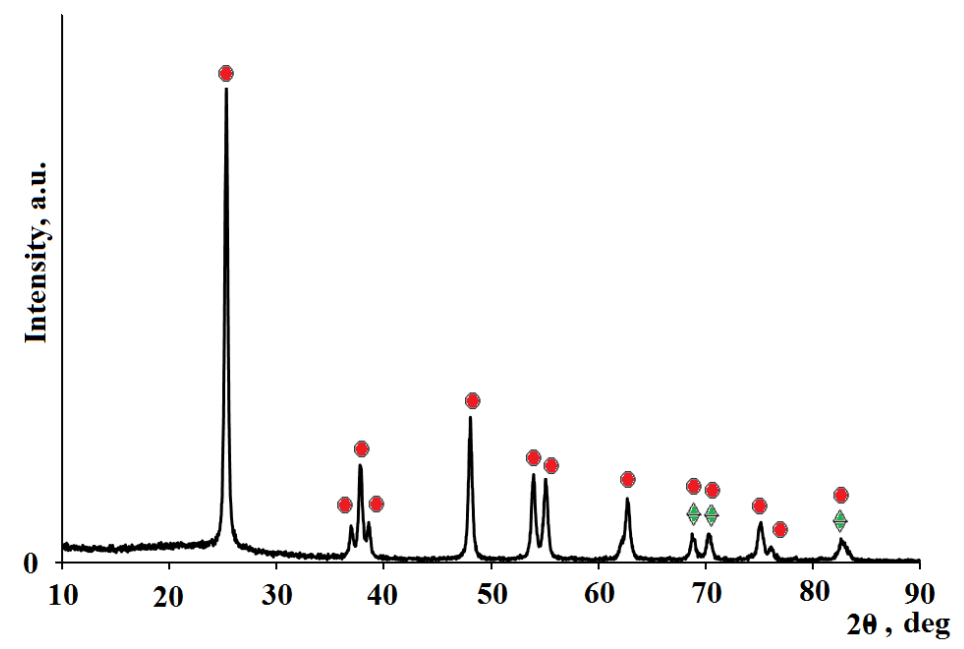

Figure 3.Diffraction patterns of samples without a rutilizing additive:

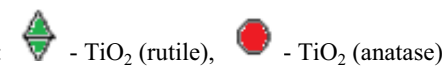




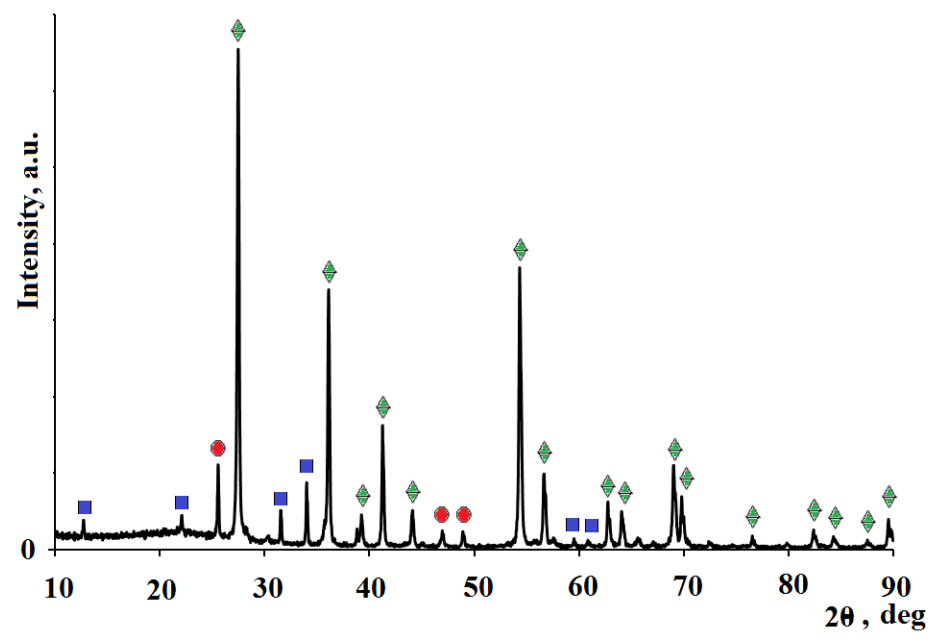

Figure 4.Diffraction patterns of samples with a rutilizing additive: $\stackrel{\Delta}{\nabla}-\mathrm{TiO}_{2}$ (rutile), $-\mathrm{TiO}_{2}$ (anatase), $\square-\mathrm{Zn}_{2} \mathrm{SiO}_{4}$ (villemit).

The results of the analysis forSample №1 (fig.3) - without addition of a rutilizingadditive, and Sample №2 (fig.4) with addition of it analyzed at the atomic emission spectrometer iCAP 6300 Duo are shown in Table 1.

Table 1.Results of element analysis at the atomic emission spectrometer iCAP 6300 Duo

\begin{tabular}{|c|c|c|c|}
\hline \multirow{2}{*}{ Denotation } & $\begin{array}{c}\text { Content of main } \\
\text { components, \% }\end{array}$ & \multicolumn{2}{|c|}{ Content of main impurities, \% } \\
\cline { 2 - 4 } & $\mathrm{Ti}$ & $\mathrm{Fe}$ & $\mathrm{Zn}$ \\
\hline Sample 1 & 58,21 & 0,29 & 0,094 \\
\hline Sample 2 & 59,75 & 0,078 & 0,23 \\
\hline
\end{tabular}

The results of the element analysis show that $\mathrm{Zn}$ metal addition decreases the content of Fe by substitution. $\mathrm{TiO}_{2}$ has a sorption activity, and, apparently, $\mathrm{Zn}^{2+}$ displaces $\mathrm{Fe}^{3+}$.

\section{Conclusion}

Based on experimental data dehydration of hydrated titanium dioxide with addition of a rutilizing additive and without it is calculated using mathematical processingwithin the range of temperatures from $100{ }^{\circ} \mathrm{C}$ to $230^{\circ} \mathrm{C}$ in time.The results of a structural analysis show as follows: addition of the rutilizing additive in the form of Znmetal decreases the temperature of thermal processing and facilitates formation of crystallization rutile centers. For speeding up the processes, which run in the intra-diffusion area, it is necessary to remove the layer inhibiting a chemical reaction fromreacting particles. It could be arranged in rotating machines.

\section{References}

1. V.A. Borisov, A.N. Dyachenko, R.I. Kraidenko,Mechanism of reaction between cobalt(II) oxide and ammonium chloride. Russian Journal of Inorganic Chemistry, Vol. 57, Issue: 4, pp 499-501, ( 2012)

2. G.G. Andreev, A.N. Dyachenko, O.E. Permyakov, Lectures on heterogeneous chemical kinetics, Tomsk:TPU Publishing, p 120 (2008)

3. A.S. Kantaev, A.L. Lashtur, Obtaining Titanium Dioxide of Rutile Form of Crystal Lattice from The Solutions Contained Fluorammonium Titanium Complex Salts // International MultiConference of Engineers and Computer Scientists: Proceedings, Hong Kong, March 16-18, 2016. - London: International Association of Engineers, - Vol. 2 pp 719-720 (2016)

4. V.V. Smirnova // Modern problems of science and education. №5(2012) 